\title{
Psychiatry in the 1880s
}

\section{Books for Asylum Doctors, 1885}

\author{
W. LI. Parry-Jones, Consultant Psychiatrist, Warneford Hospital, Headington, Oxford
}

Book reviews published in professional journals provide an interesting glimpse of contemporary interests, ideas and attitudes. The third number of the Journal of Mental Science (formerly Asylum Journal) included book reviews and, after appearing intermittently for a while, they became a regular feature throughout the remainder of the nineteenth century. These reviews were probably the principal source of information for asylum doctors about current books in their field, although there were a small number of alternatives for the more specialist readers.

The Journal of Psychological Medicine and Mental Pathology ran from 1848 to 1860 continuing, for a short while, as the Medical Critic and Psychological Journal, 1861-3. Later, a new series of the Journal of Psychological Medicine ran from 1875 to 1883 . In keeping with its literary and philosophical style, this journal included a small number of lengthy reviews in each number. Brain: $A$ Journal of Neurology, was established in 1878, and from the outset its issues often included notices of books. As one of its editors was J. C. Bucknill, a very prominent member of the Medico-Psychological Association, it is not surprising that these included a number on insanity, but few of the original articles in this journal would have been of much direct interest to asylum doctors. Similarly, Mind: $A$ Quarterly Review of Psychology and Philosophy, first published in 1876, included a small number of key works in the field of insanity. The American Journal of Insanity was established in 1844, but it seems unlikely that it would have constituted a resource of information about books for many provincial asylum doctors in Britain.

In 1885, the quarterly numbers of the Journal of Mental Science included a total of 23 reviews, a number that seems surprisingly small compared with the multitude published a century later (e.g. 230 reviews in 1984). The material reviewed covered a wide range as the following breakdown of subject matter of the books indicates: neurology (5), philosophy (4), psychology (3), official reports (3), general works on insanity (2), legislation (2), hospital construction and management (1), biography (1), general medicine (1), pathology (1). Two books were in French and one in German. The reviews were usually anonymous or, occasionally, were initialled in ways that made their authors easy to identify. They were often lengthy, certainly by present-day standards, although they display a familiar emphasis on common sense, clinical observation, and the avoidance of verbosity. Indeed, in a piece on S. V. Clevenger's Comparative Physiology and Psychology ${ }^{1}$ the reviewer noted that: 'For cosmopolitan readers, numerous Americanisms, if omitted, would render the meaning of many pithy sen- tences much clearer.' Plus ça change, plus c'est la même chose.

It was standard practice a century ago to review the annual reports of the Commissioners in Lunacy for England and Wales and for Scotland and also those of the Inspectors of Irish Asylums. In 1885, the Thirty-Eighth Report of the Commissioners in Lunacy ${ }^{2}$ was, as usual, voluminous and thought to contain 'a large amount of interesting and valuable material'. It is likely that asylum doctors would have found it particularly interesting to read the statistical evidence that: 'There is no appreciable increase in occurring insanity, and that there has been none during the last eight years'. However, there had been an overall increase in asylum inmates, 'almost entirely due to accumulation of chronic cases of the pauper class'. This had been a major problem for some time and continued to defy solution for decades to come.

The Scotch Lunacy Report ${ }^{3}$ was 'as usual, distinguished for minuteness, and a kindly sort of prolixity which is not altogether out of keeping with the personal attention to details for which the Board has long been noted'. This was a period when the Commissioners in Lunacy for Scotland were committed to the social and financial benefits of accommodating lunatics in private dwellings as an alternative to asylum care. This method of relieving the pressure on over-crowded asylums never really found favour south of the border, and a reviewer in 1885 castigated the Commissioners for being so partisan:

We consider that by their praiseworthy efforts and indefatigable exertions many lunatics are suitably provided for at a cheap rate, who in a more densely populated country would have to be sent to an asylum. But the system is quite strong enough to speak for itself without there being any necessity for surrounding it with the torrent of arguments which might be as readily used for swamping as for irrigating it, and it is weakened by an attempt to advocate its extension to totally unsuitable cases.

Clearly, nineteenth century asylum doctors were not in awe of their distinguished colleagues, the Commissioners, and, indeed, many reviews were very direct and hardhitting.

It is interesting that the crop of books in 1885 only included two general works on insanity. Both were new editions of old favourites, by former Presidents of the Medico-Psychological Association. Fielding Blandford's Insanity and its Treatment ${ }^{4}$ was in its third edition and attracted a short, positive review, particularly because: 'The statements made and the opinions expressed to a very large extent closely followed Nature, and being based on 
observation are good for all time'. The only ground for criticism was the inadequate discussion of moral insanity. The work by W. H. O. Sankey, ${ }^{5}$ however, commanded lengthy and detailed consideration, particularly of the author's views about the classification of disorders. Sankey held the unorthodox view that most cases of insanity could be comprehended under the general term "ordinary insanity'. Although cases varied in their course and progress, he maintained that all cases should be regarded as of one species throughout, 'such is the rule in general pathology, and there are no grounds for having a different system in insanity, however long the case may last'. He illustrated this view by citing a case in which the primary attack might present with symptoms of melancholy, which might either subside or result in the patient's death. Alternatively, the disease could exhibit symptoms of violence or acute mania. Chronic states of mania or melancholy might supervene and ultimately final stages of imbecility or dementia might ensue. The reviewer noted that:

No-one can deny that this is a striking view, and no careful observer can doubt that in some points it is very noteworthy, that the question arises, has not the author's reasonable dislike to the over-refinement of classification led him too far? Does he not generalise too much? In fine, is this course of insanity, as he strictly lays it down, truly in accordance with clinical experience? We think few of our readers will endorse Dr Sankey's view in its entirety.

Considerable attention was given to works from neurology. This was not surprising in view of the continuous hope that study of the brain would shed fresh light on mental disease. The works reviewed ranged from $\mathbf{W}$. $\mathbf{R}$. Gowers' major work, Lectures on the Diagnosis of Diseases of the Brain, ${ }^{6}$ to highly specialised texts on aphasia in French, on giddiness and on sclerosis of the spinal cord. The latter, by J. Althaus, ${ }^{7}$ were included for review on the naive-sounding grounds that in the pathology of the simplest structure will lie the promise of the pathology of the more complex structure'. Concern with morbid anatomy even led the reviewers to include A. B. Lee's The Microtomist's Vade-Mecum, ${ }^{8}$ a volume of under 500 pages containing 'all that is required by the practical section cutter'. Of course, asylum doctors were encouraged to carry out post-mortem examinations and, in fact, in 1885, the Commissioners in Lunacy were pleased to report that nearly 69 per cent of deaths in asylums were being verified in this way. The quality of such work, however, and the research value of the post-mortem findings in the nineteenth century was never high. The reviewer of Lee's monograph lamented that: 'One of the dreams of our youth, and a fading dream of maturer years, was that some central establishment for pure research into pathological conditions occurring in the brain of the insane might be formed under the guidance of the Medico-Psychological Association, but the genius for this has not yet arisen.'

Two lengthy conjoint reviews, each extending to over ten pages, highlight the major interest in the materialist, physiological approach to the understanding of the mind and its disorders, as well as the concern felt for some of the adverse implications. In reviewing the two pamphlets by the philosopher, W. H. Walshe, ${ }^{9.10}$ the question arises as to whether the search for scientific truth leads inevitably to atheism. In this respect, the reviewer, probably W. H. $\mathbf{O}$. Sankey, endorses Walshe's conclusion that: 'Biology seems to be, in truth, the working instrument of possible indirect revelation granted to man, in respect of this special enigma by the Almighty First Cause' and that, ' $\ldots$. scarcely can we, in our most ardent moments of scientific enthusiasm, hope through physiology to fathom the mystery to its lowest depth-to grasp the true nature of the force that sets to work the dynamic and statical activities evolving mental phenomena out of brain.'

The comparative review of two remarkable books by T. H. Green, Prolegomena to Ethics ${ }^{11}$ and Henry Maudsley, Body and Will, ${ }^{12}$ points out the wide divergence of the materialistic and idealistic currents in English thought. Green's philosophical views are that nature and matter have no reality. These are set in stark contrast to Maudsley's forthright conclusions that: 'Mind and all its products are a function of matter, an outcome of interacting and combined atomic forces not essentially different in kind from the effervescence that follows a chemical combination or the explosion of a fulminate.' By 1885 , Maudsley's writing, disparaging psychological approaches to mental disorder and their replacement by somaticist views, had had far-reaching effects on Victorian psychological medicine. ${ }^{13}$

A decade earlier he had made it explicit that: 'It is not our business, as it is not in our power, to explain psychologically the origin and nature of any of these depraved instincts; it is sufficient to establish their existence as facts of observation, and to set forth the pathological conditions under which they are produced; they are facts of pathology, which should be observed, and classified like other phenomena of disease. ${ }^{14}$ Mental disorders, therefore, were simply nervous disorders, like epilepsy, in which mental symptoms were prominent. The therapeutic barrenness of such views, however, was soon apparent, creating the setting for the emergence yet again of dynamic approaches, but this time, with Sigmund Freud waiting in the wings.

\section{REFERENCES}

'Clevenger, S. V. (1885) Comparative Physiology and Psychology. Chicago: Jensen, McClurg.

${ }^{2}$ Commissioners in Lunacy (1884) Thirty-Eighth Annual Report, 17 th July.

${ }^{3}$ Commissioners in Lunacy for SCotland (1884) Twenty-Sixth Annual Report.

${ }^{4}$ BLANDFORD, F. (1884) Insanity and its Treatment: Lectures on Treatment, Medical and Legal, of Insane Patients. Edinburgh: Oliver \& Boyd.

SSANKEY, W. H. O. (1884) Lectures on Mental Disease. London: Lewis.

${ }^{6}$ GowErs, W. R. (1885) Lectures on the Diagnosis of Diseases of the Brain. London: J. \& A. Churchill.

'Althaus, J. (1885) On Sclerosis of the Spinal Cord. London: Longmans. 
${ }^{8}$ Lee, A. B. (1885) The Microtomist's Vade-Mecum. London: J. \& A. Churchill.

${ }^{9}$ Walshe, W. H. (1884) Physiology versus metaphysics in relation to mind. Lancet, $i 1-3 ; 51-53$.

10__ (1885) The Colloquial Linguistic Faculty and its Physiological Groundwork. London: J. Bale.

${ }^{11}$ Green, T. H. (1883) Prolegomena to Ethics (ed. A. C. Bradley). Oxford: Clarendon Press.
${ }^{12}$ Maudsley, H. (1883) Body and Will. London: Kegan Paul.

${ }^{13}$ Clark, M. (1981) The rejection of psychological approaches to mental disorder in late nineteenth-century British psychiatry. In Madhouses, Mad-Doctors, and Madmen (ed. A. Scull). London: Athlone Press.

${ }^{14}$ Maudsley, H. (1874) Responsibility in Mental Disease (p. 154).

London: Kegan Paul.

\title{
Psychiatric Teaching in Malaya*
}

\author{
Nicholas Rose, Lecturer in Psychiatry, Warneford Hospital, Oxford
}

Like it or not, we all live on a planet teeming with variety. East and West for example have developed very differently, even though many of the problems faced by these divergent cultures are similar. True, Europe's colonising yoke in the past four hundred years introduced western infrastructure to many eastern countries, particularly in the fields of administration, communication, health, and education. However, traditional habits run deep, particularly in countries with large rural populations, and the apparent degree of westernisation can be deceptive.

I found myself having to think about these issues when I accepted a teaching post in which I was expected to help adapt a peculiarly western teaching programme to a brand new eastern medical school, in Penang, Malaya. The western teaching method emphasised students being given a much more active and responsible role in the learning process, as well as encouraging peer group discussion and constant questionning of facts and theories. In contrast, the local oriental culture emphasised the importance of obedience, not questionning your elders, passivity in the learning process, and a relative lack of emphasis on assertiveness and individualism.

Of course, importing western ideas en bloc initially produced problems, and I shall discuss these together with lessons that we in the West might learn from the experience. First, however, I will describe the teaching methods adopted in Penang, and the implications they had for the teaching of psychiatry.

What I will not do (well, only briefly!) is describe the ravishing tropical beauty of Malaya; the tropical rain forest steaming after a thunder burst; the smell of a million cloves browning in the sun; the glimpses of an infinitely older orient uniquely preserved in corners of Penang, giving visions of a China that no longer exists. This was the luscious backdrop in front of which the circumstances to be described occurred.

The medical school in Penang began taking students in the year of my arrival, 1981. From the beginning the school decided to adopt the most up-to-date methods and

* Based on a talk given in Autumn 1984 at the University Department of Psychiatry, Warneford Hospital, Oxford. committed itself to two major teaching priorities. Firstly, to develop an integrated curriculum where departmental and clinical/non-clinical boundaries would be swept aside; secondly, to present the curriculum through a series of problem-solving exercises in which student initiative was encouraged. I am sure both themes are well known to McMaster, Flinders, and Newcastle (NSW) buffs, and perhaps may even be familiar day dreams to some of those working in traditional medical schools.

The demands of an integrated, problem-based curriculum meant that the teaching of all subjects, including psychiatry, had to be planned firstly so as to integrate with the teaching of other disciplines, and secondly so as to present the subject through a sequence of problems, the solutions of which required students to identify and track down relevant parts of the curriculum. This process greatly emphasised student participation. Discussion, problem solving, and identification of learning resources was done in small groups, where the teacher aimed to stimulate students to enquire in the right direction rather than to act as a fountain of knowledge. Printed on the back of every tutor's brain were the words: 'Never do for students what they can do for themselves'!

The first three years of the medical course were presented in this fashion, and during this time students would be introduced to the core psychiatric curriculum (approximately 75 hours) in addition to having about ten sessions of clinical experience with psychiatric patients. The more traditional five-week psychiatric unit attachment then took place during the fourth year.

An example of a problem given early in the second year was acute shortness of breath in a young woman. Through discussion in small groups, facilitated by a tutor, students were expected to list what they needed to know in order to fully understand the intricacies of the problem and its potential consequences and management. In this case, information from a range of potentially interacting disciplines was needed including physiology, anatomy, general medicine, and psychological medicine. Each discipline provided information in the form of learning packages, demonstrations, seminars, and occasionally lectures. Once students had worked through this learning material, they would meet for a second group session. An initial dis- 